\title{
TREATMENT OF SCAPHOID NONUNION WITH OLECRANON BONE GRAFT AND COMPRESSION SCREW
}

\author{
antonio Tufi Neder Filho ${ }^{1}$, Eduardo Traldi Franceschinl ${ }^{2}$, Arlindo Gomes Pardini Júnior ${ }^{2}$, Marcelo Riberto ${ }^{3}$, Nilton Mazzer ${ }^{3}$ \\ 1. Hospital Lifecenter, Belo Horizonte, MG, Brazil. \\ 2. Hospital Ortopédico, Belo Horizonte, MG, Brazil. \\ 3. Universidade de São Paulo, Faculdade de Medicina de Ribeirão Preto. Ribeirão Preto, SP, Brazil.
}

\section{ABSTRACT}

Objective: To evaluate the outcome of olecranon bone graft and compression screw for the treatment of nonunion of the Lichtman type I scaphoid. Method: We evaluated 15 patients of 32 who underwent surgical treatment for nonunion of the Lichtman type I scaphoid with olecranon bone graft and screw compression. Results: We obtained 100\% consolidation in our sample. The mean flexion of the wrist on the affected side was $68^{\circ}$ and $75^{\circ}$ on the non-affected side. The average extension was $63^{\circ}$ and $72^{\circ}$, respectively. The average grip strength was $35 \mathrm{kgf}$. This corresponds to $98 \%$ of the handgrip strength of the non-affected side, which was $37 \mathrm{kgf}$. The DASH score averaged 5 points. Conclusion: We believe that the use of bone graft obtained from the olecranon and secured with cannulated screw is a resolute technique for cases of linear nonunion of the Lichtmann type I scaphoid. It has the advantages of a new anesthesia for removal of the graft and the access is easy, providing a good exposure for removal and good aesthetic results. Level of evidence IV.

\section{Case series.}

Keywords: Scaphoid bone. Pseudarthrosis. Bone transplantation.

Citation: Neder Filho AT, Franceschini ET, Pardini Junior AG, Riberto M, Mazzer N. Treatment of scaphoid nonunion with olecranon bone graft and compression screw. Acta Ortop Bras. [online]. 2016;24(3):159-63. Available from URL: http://www.scielo.br/aob.

\section{INTRODUCTION}

The scaphoid bone is the most commonly fractured carpal bone, corresponding to 60 to $70 \%{ }^{1}$ of these fractures. It ranks second in relation to the wrist bones, radial distal fracture ${ }^{1}$ being the most common. This fracture often goes unnoticed in the acute phase due to various factors including stress and the difficulty to be evaluated by plain radiography. Moreover, the doctor's tendency is to concern about the most frequent fracture, which is the distal radial fracture. ${ }^{2}$ Heo et al. ${ }^{3}$ reported an incidence of $20.9 \%$ of fractures of the carpal bones associated to distal radial fractures.

Approximately $80 \%$ of the scaphoid bone surface is covered with cartilage. The main arterial blood supply is retrograde coming from the radial artery branch. Therefore, in the scaphoid fracture, the arterial blood supply to the proximal pole may be interrupted. ${ }^{2}$

The difficult diagnosis of scaphoid fracture can often lead to consolidation by intramembranous ossification. Immobilization is necessary for the proper formation of bone callus. The complications are associated with forces that cause this bone to move that, associated with its delicate vasculature, causing a high rate of nonunion. ${ }^{1}$ If undiagnosed or not treated properly, the natural evolution tends to nonunion, with subsequent posterior arthrosis and instability, leading to carpal collapse, known as "scaphoid nonunion advanced collapse" (SNAC). It has a high risk of necrosis of the proximal pole due to reduced vascularity. ${ }^{4}$

The gold standard treatment of nonunion of the scaphoid without arthrosis or instabilities, classified as Lichtmann grade I, is still the Matti-Russe technique, which uses cancellous bone graft to help consolidation. ${ }^{5}$

In this study we assessed patients with Lichtmann grade I scaphoid nonunion undergoing volar treatment with cancellous bone graft taken from the olecranon and fixed with cannulated screw.

\section{MATERIALS AND METHODS}

In this study 52 patients undergoing surgery for scaphoid nonunion were evaluated from the hospital's database from January 2008 to December 2012. Inclusion criteria selected patients with Lichtmann grade I nonunion. Exclusion criteria were other levels of the aforementioned classification, patients with fractures in the proximal pole, previous wrist injury, instabilities, trans-scaphoid perilunate fracture dislocation, and necrosis of

All the authors declare that there is no potential conflict of interest referring to this article. 
the proximal pole. Of the 52 initial patients 32 were selected, and only 15 showed up for evaluation. Thirteen patients have not been found and four refused to participate since they had no complaints. The selected patients were surgically treated in our hospital between January 2008 and December 2013. Therefore, these patients were at six months to five years postoperative period. All of them were surgically treated by volar fixation with cannulated compression screws and olecranon cancellous bone graft.

The study was approved by the hospital ethics committee, protocol CAAE 47957015.0.0000.5126, and all patients signed a Free and Informed Consent form before the surgery. Data on age, affected side, gender, and DASH test results were recorded. These 21 patients were tested for their ability to perform specific functions and checking for symptoms. They were tested for mobility by flexion and extension range of motion both for the affected and the contralateral wrist using a goniometer. Pain resulting from fossa radialis (anatomical snuffbox) palpation or thumb pistoning was also recorded. The wrist prehension strength tests compared to the contralateral side were performed using a Jamar dynamometer (Sammons Preston, Bolingbrook, IL, USA). These tests were performed three times on each side with the elbow flexed $90^{\circ}$ and forearm in neutral rotation. The results were divided by three to obtain the final average for each side. ${ }^{6}$ The radiographic evaluation was made through the images in the following positions: neutral PA; PA with ulnar deviation of the wrist; profile; semi pronation oblique; and semi-supination oblique. (Figure 1)

The fracture was considered consolidated according to the presence of trabecular bone in at least three views without pain on the fracture site. ${ }^{7}$ We considered DISI when the scapholunate angle was larger than $60^{\circ}$ or the radio-lunar angle was larger than $30^{\circ} .{ }^{8}$ Surgery was performed with the patient in the supine position under brachial plexus anesthesia associated with sedation and pneumatic tourniquet. The volar access was between the flexor carpi radialis and the radial artery, ${ }^{9}$ exposing the nonunion focus, local curetted, fixated with a wire guide in the longitudinal axis of the scaphoid with fluoroscopic confirmation and another anti rotational wire parallel to the first one. We indirectly confirmed the screw size with a second guidewire. A tunnel was drilled with a drill and a circa $2 \mathrm{~cm}$ longitudinal dorsal access was done in the proximal third of the forearm over the ulna, $4 \mathrm{~cm}$ distal to the olecranon apex and a circa $1 \mathrm{~cm}^{2}$ window was opened with an osteotome in the dorsal cortical bone of the proximal ulna and a curette graft was inserted for collection of cancellous bone. Impacted bone graft in the focus of the scaphoid nonunion and a screw was inserted with intrafocal compression. (Figure 2)

The position and size of a suitable screw were confirmed under fluoroscopy. Suture was done with nylon 4-0. Dressing with open gauze and placed plaster cast covering proximal phalanx from the thumb to the forearm. After 15 days the stitches were removed, but the plaster cast was maintained for six weeks. After six weeks and confirming the consolidation through radiographs, the plaster cast was removed and physiotherapy sessions for range of motion gain were started. As in preoperative evaluation, (Figure 1) intra-operative images (Figure 2) and one month postoperative images were taken (Figure 3).

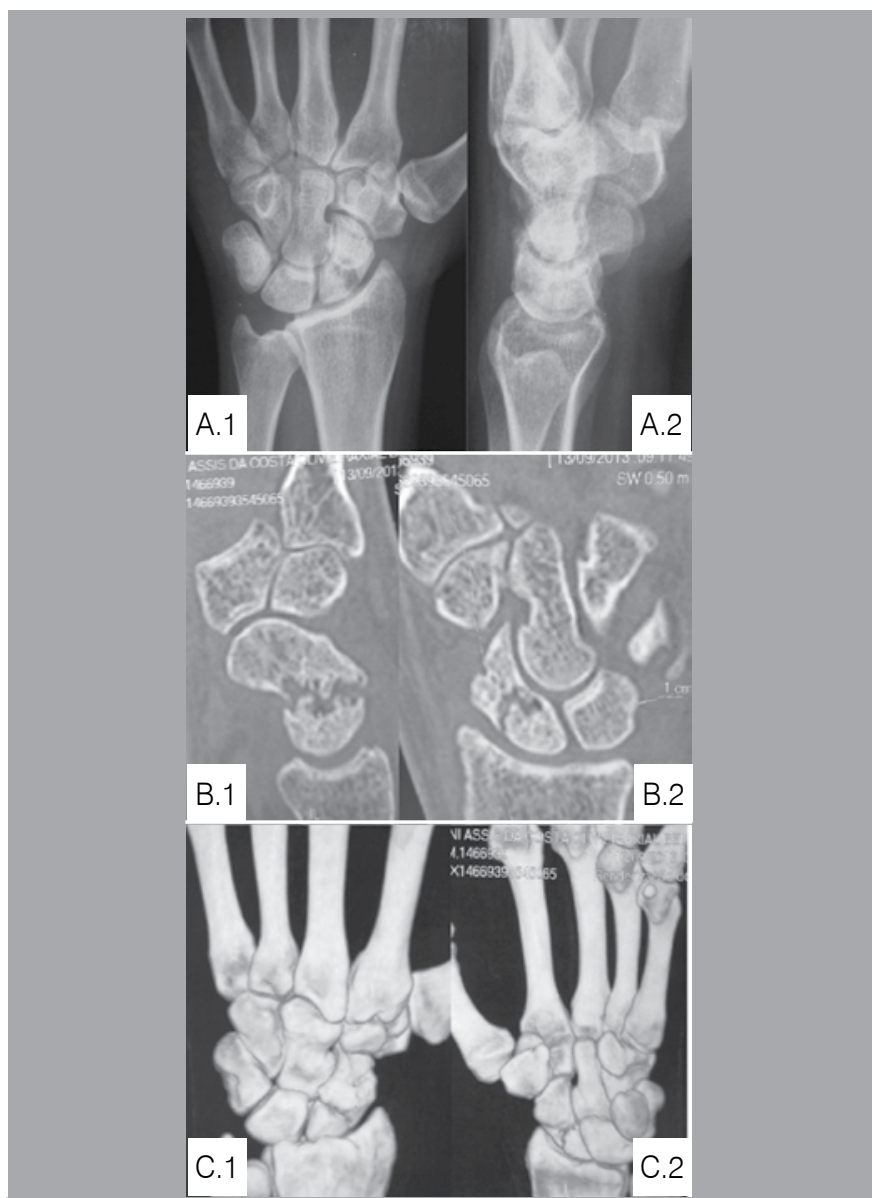

Figure 1. (A1 and A2) Preoperative anteroposterior and profile x-ray of the wrist (patient A) showing scaphoid nonunion, with no signs of arthrosis or Lichtmann grade 1 carpal instability; (B1 and B2) Sagittal and coronal sections Computed Tomography with good delimitation of bone resorption of nonunion focus without major angular change. (C1 and C2) 3D Reconstruction images of the wrist.

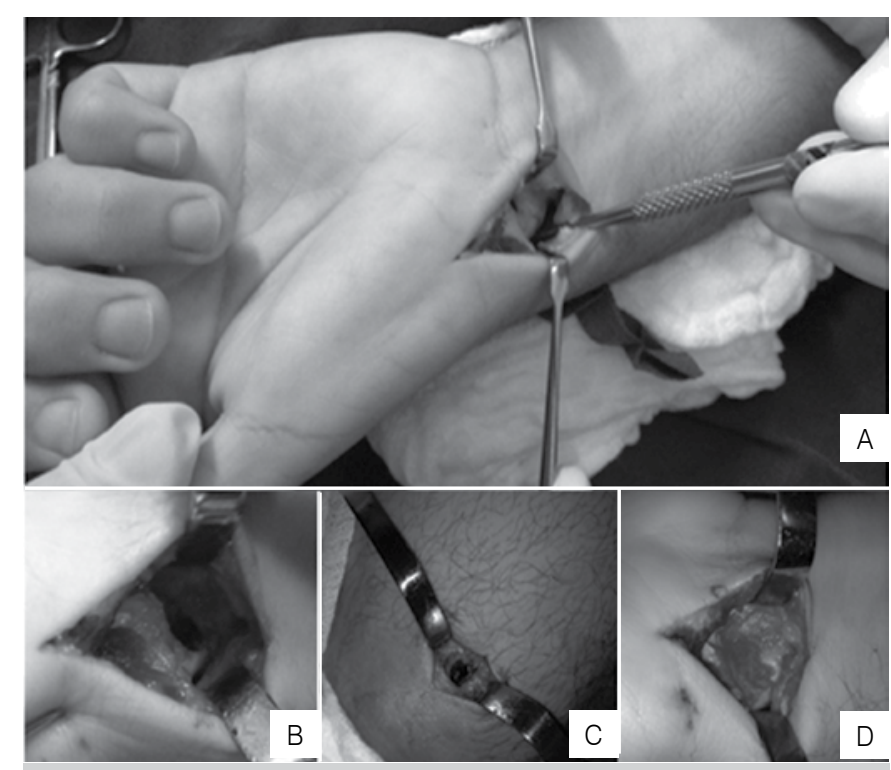

Figure 2. Intra-operatory photos (Patient A ). A: Volar access between carpal radial flexor and radial artery and aspect of bone resorption at scaphoid nonunion; B: Curetted nonunion focus; C: Elbow access for removal of olecranon bone graft; (D) Scaphoid nonunion focus filled with graft. 


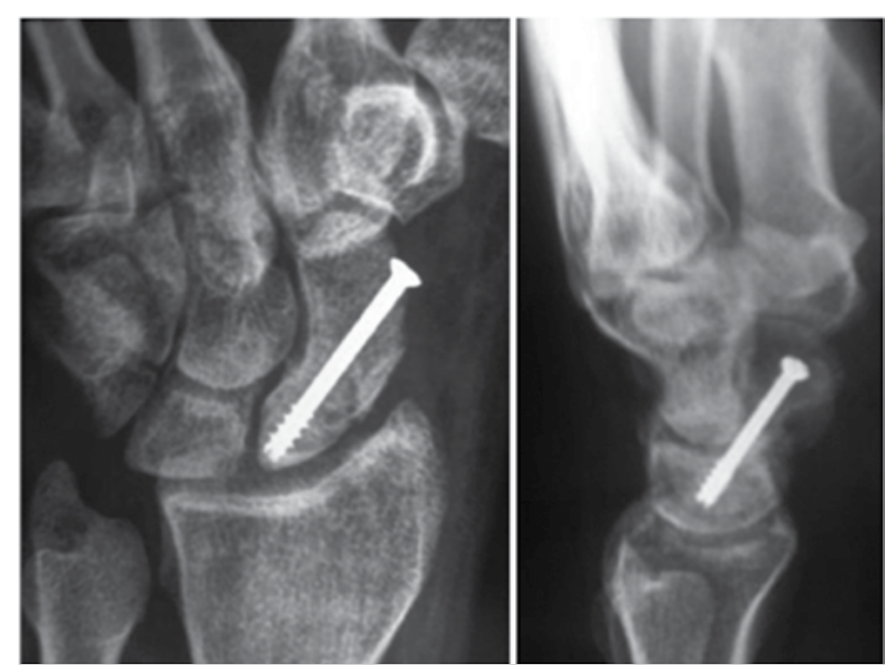

Figure 3. Antero-posterior and profile x-ray of wrist at one month postoperative with no signs of graft reabsorption. Patient $A$

\section{RESULTS}

Of the 15 operated patients who attended evaluation consultation, all were men aged 20-38 years (mean 26 years old), the affected side was the right side in eight patients and the left side in seven patients. The mean follow-up time ranged between six months and five years between January 2008 and January 2013.

Of the revised medical records, both clinical and radiographic consolidation occurred at all patients without surgical reintervention. No infections, dehiscence or pain complaints at the graft removal site have been reported. In the final clinical evaluation no functional disability, signs of scaphoid necrosis or posttraumatic arthrosis and thumb stiffness were reported. All patients informed that they continue to perform their prior to surgery activities.

As post-surgical complication we report one patient, at the seventh postoperative month, who showed marked loss of flexion-extension of the wrist, between $31^{\circ}$ extension and $28^{\circ}$ flexion, probably due to not having followed postoperative rehabilitation guidelines.

In the range of motion assessment, the mean wrist flexion at the affected side was $68^{\circ}$ and the non-affected side $75^{\circ}$ (range $49^{\circ}$ to $75^{\circ}$ ). The mean extension was $63^{\circ}$ on the affected side and $72^{\circ}$ of the non-affected side (ranging from $47^{\circ}$ to $69^{\circ}$ ). The mean grip strength was $35 \mathrm{kgf}$, corresponding to $98 \%$ of the nonaffected hand (37 kgf, ranging from $33 \mathrm{kgf}$ to $38 \mathrm{kgf}$ ). (Table 1) The DASH functional test showed average score of 5 points. To one patient, whose leisure activity was playing the trumpet and conducting an orchestra, the specific questionnaire for musicians was applied. He scored zero at both the specific and non-specific questionnaires. (Table 1)

Table 2 shows the descriptive analysis of grip strength, range of flexion-extension and DASH questionnaire results. We found that only DASH showed high variability, because the variability coefficient is greater than $50 \%$. The average DASH score was 5.0 points (ranging from 2.0 to 8.0 ).

We used the Wilcoxon test to compare the results on strength, arc of flexion and extension of the wrist between affected and unaffected sides. This test was used because the data is paired, i.e., when the same subject is research and control of himself; $p$-value is the result of each comparison. (Table 3)

\begin{tabular}{|c|c|c|c|c|c|}
\hline Patient & $\begin{array}{l}\text { Prehension } \\
\text { strength } \\
\text { Affected } \\
\text { side/Non- } \\
\text { affected } \\
\text { side (Kgf) }\end{array}$ & $\begin{array}{c}\text { Pain at } \\
\text { anatomical } \\
\text { snuffbox } \\
\text { palpation } \\
\text { or thumb } \\
\text { pistoning }\end{array}$ & $\begin{array}{l}\text { Arc of } \\
\text { movement } \\
\text { Flexion } \\
\text { (degrees) }\end{array}$ & $\begin{array}{c}\text { Extension } \\
\text { Affected side/ } \\
\text { Non-affected } \\
\text { side }\end{array}$ & $\begin{array}{c}\text { DASH } \\
\text { (points) }\end{array}$ \\
\hline 1 & $34 / 35$ & No & $73 / 75$ & $66 / 73$ & 0 \\
\hline 2 & $37 / 36$ & No & $68 / 74$ & $64 / 71$ & 3 \\
\hline 3 & $35 / 37$ & No & $75 / 76$ & $67 / 74$ & 0 \\
\hline 4 & $34 / 36$ & No & $70 / 77$ & $64 / 75$ & 10 \\
\hline 5 & $34 / 40$ & No & $49 / 80$ & $47 / 75$ & 18 \\
\hline 6 & $34 / 37$ & No & $71 / 73$ & $66 / 70$ & 7 \\
\hline 7 & $35 / 35$ & No & $66 / 74$ & $60 / 71$ & 0 \\
\hline 8 & $35 / 39$ & No & $65 / 73$ & $60 / 70$ & 8 \\
\hline 9 & $36 / 38$ & No & $68 / 76$ & $63 / 72$ & 2 \\
\hline 10 & $34 / 37$ & No & $67 / 74$ & $64 / 69$ & 15 \\
\hline 11 & $38 / 34$ & No & $70 / 72$ & $65 / 69$ & 0 \\
\hline 12 & $35 / 36$ & No & $68 / 76$ & $64 / 73$ & 0 \\
\hline 13 & $35 / 40$ & No & $67 / 74$ & $62 / 72$ & 8 \\
\hline 14 & $37 / 37$ & No & $72 / 75$ & $69 / 72$ & 0 \\
\hline 15 & $32 / 38$ & No & $71 / 76$ & $64 / 74$ & 4 \\
\hline
\end{tabular}

Table 2. Complete descriptive for prehension strength, arc of movement, extension and DASH.

\begin{tabular}{c|c|c|c|c|c|c|c}
\hline \multirow{2}{*}{ Descriptive } & \multicolumn{2}{|c|}{$\begin{array}{c}\text { Prehension } \\
\text { strength }\end{array}$} & \multicolumn{2}{|c|}{ Arc of movement } & \multicolumn{2}{|c|}{ Extension } & \multirow{2}{*}{ Affected } \\
side & $\begin{array}{c}\text { Non- } \\
\text { affected } \\
\text { side }\end{array}$ & $\begin{array}{c}\text { Affected } \\
\text { side }\end{array}$ & $\begin{array}{c}\text { Non- } \\
\text { affected } \\
\text { side }\end{array}$ & $\begin{array}{c}\text { Affected } \\
\text { side }\end{array}$ & $\begin{array}{c}\text { Non- } \\
\text { affected } \\
\text { side }\end{array}$ & \\
\hline Mean & 35.0 & 37.0 & 68.0 & 75.0 & 63.0 & 72.0 & 5.0 \\
\hline Median & 35 & 37 & 68 & 75 & 64 & 72 & 3 \\
\hline $\begin{array}{c}\text { Standard } \\
\text { deviation }\end{array}$ & 1.5 & 1.8 & 5.9 & 2.0 & 5.0 & 2.0 & 5.9 \\
\hline CV & $4 \%$ & $5 \%$ & $9 \%$ & $3 \%$ & $8 \%$ & $3 \%$ & $117 \%$ \\
\hline Min & 32 & 34 & 49 & 72 & 47 & 69 & 0 \\
\hline Max & 38 & 40 & 75 & 80 & 69 & 75 & 18 \\
\hline $\mathrm{N}$ & 15 & 15 & 15 & 15 & 15 & 15 & 15 \\
\hline $\mathrm{Cl}$ & 0.8 & 0.9 & 3.0 & 1.0 & 2.5 & 1.0 & 3.0 \\
\hline
\end{tabular}


Table 3. Side comparison for strength arc of movement, flexion and extension.

\begin{tabular}{|c|c|c|c|c|c|c|c|}
\hline \multicolumn{2}{|c|}{ Side } & Mean & Median & Standard & $\mathrm{N}$ & $\mathrm{Cl}$ & p-value \\
\hline \multirow{2}{*}{$\begin{array}{l}\text { Prehension } \\
\text { strength }\end{array}$} & Affected side & 35.0 & 35 & 1.5 & 15 & 0.8 & \multirow{2}{*}{0.017} \\
\hline & $\begin{array}{l}\text { Non-affected } \\
\text { side }\end{array}$ & 37.0 & 37 & 1.8 & 15 & 0.9 & \\
\hline \multirow{2}{*}{ Flexion } & Affected side & 68.0 & 68 & 5.9 & 15 & 3.0 & \multirow[b]{2}{*}{0.001} \\
\hline & $\begin{array}{l}\text { Non-affected } \\
\text { side }\end{array}$ & 75.0 & 75 & 2.0 & 15 & 1.0 & \\
\hline \multirow[b]{2}{*}{ Extension } & Affected side & 63.0 & 64 & 5.0 & 15 & 2.5 & \multirow[b]{2}{*}{0.001} \\
\hline & $\begin{array}{l}\text { Non-affected } \\
\text { side }\end{array}$ & 72.0 & 72 & 2.0 & 15 & 1.0 & \\
\hline
\end{tabular}

\section{DISCUSSION}

Scaphoid fractures often go unnoticed through the initial X-rays, that detect only about $70 \%$ of them. Other diagnostic tests include computed tomography, bone scintigraphy, MRI, and ultrasound. ${ }^{2} \mathrm{MRI}$ was considered the gold standard ${ }^{5}$ and computed tomography with technological development has gained more diagnostic importance. ${ }^{10}$ Yildirim et al. ${ }^{11}$ suggested that ultrasound evaluation in the emergency room would increase the diagnostic power of this injury.

The fracture mechanism was generally fall with the flat hand in dorsiflexion and radial deviation of the wrist. ${ }^{12}$ There are a number of treatment techniques for scaphoid nonunion without signs of SNAC or necrosis of the proximal pole (Lichtmann grade I), such as percutaneous screws fixation with or without bone graft, ${ }^{10}$ fixation with Kirschner wires, ${ }^{13}$ vascularized bone graft, $, 914,15$ and others that report using different types of screws.

Despite advances in surgery and in the understanding of bone healing, bone nonunion remains a challenge. Autologous bone grafts is still a standard with low postoperative pain in the donor area, good aesthetic result with a $1.5-2.0 \mathrm{~cm}$ longitudinal scar at the posterior elbow region. Moreover, it is a little exposed area for graft extraction reducing, thus, the risks of another anesthesia. It is a surgically accessible region with good exposure for the small amount of soft tissue. The consolidation ratio in this study was $100 \%$ within the standards for autologous bone graft. ${ }^{16}$

We believe that a suitable patient selection for this type of surgery is important. We do not use this technique in patients with fractures of the proximal pole, tuberosity fractures, previous wrist injury, scaphoid semilunate dissociation, scaphoid perilunate fracture dislocation, humpback deformity, or avascular necrosis. It was important, at the radiographic evaluation, an angle measurement: if the radio-lunate angle is greater than $30^{\circ}$ and the radius scapholunate is greater than $60^{\circ 10}$ it was necessary to employ the Fisk-Fernandez technique to correct $\mathrm{DISI}^{5}$ using a wedge graft bone from the iliac crest. For advanced degrees of SNAC or necrosis of the proximal pole other techniques may be indicated, such as rescue techniques, including the four corners arthrodesis, ${ }^{4}$ resection of the first carpal row, radiocarpal arthrodesis, ${ }^{17}$ pure scaphoid excision ${ }^{18}$ or the pyrocarbon prosthesis, ${ }^{4,17,19}$ considering the proper indication in each case.

In our series we chose to use bone graft taken from the olecranon because we considered that this option dispenses the approach in other body segments, limiting the procedure to the limb to be operated, thus, avoiding additional anesthesia. Moreover, it is a donor region easily accessible with little visual exposure, favoring the aesthetic aspect.

The limitations identified in this study were the small number of cases due to the fact that scaphoid nonunion is relatively rare, allied to the difficulty in getting patients to return for evaluation. In the postoperative radiographic evaluation no patients presented DISI or signs of SNAC and arthrosis. All patients showed signs of trabecular bone in at least three radiographic views. Signs of impact in the trapezium screw head were found in four patients with bone remodeling at the trapezoid base, but none complained or had functional restrictions. The scaphoid nonunion was due to lack of stability and adequate reduction, to a vascularity reduction and also the forces the wrist bone is subject. ${ }^{20}$ The delay in proper immobilization for more than one month in the case of acute fracture would increase this incidence. ${ }^{12}$ Compression screws to the scaphoid in cases of nonunion showed excellent results with $91-100 \%$ consolidation rates. ${ }^{10,13}$

Abassi et al. ${ }^{21}$ enumerated the advantages of screw fixation, including acute fractures, with accelerated rehabilitation and early return to work and good results. Ya'ish et al. ${ }^{17}$ described advantages in carrying out this fixation with bioabsorbable screws, as reduced risk of later removal of the implant, thus, avoiding the difficulties and risks of a surgery. According to Kirkham and Millar ${ }^{13}$ fixation with compression screws in cases of DISI and cortical-cancellous bone graft is technically demanding. According to their research results with fixation only with Kirschner wires are compatible or even better as compared to other techniques. Léon et al. ${ }^{14}$, Malizos et al..$^{22}$ and Liang et al. ${ }^{23}$ showed $100 \%$ consolidation with vascularized bone graft based on different arterial supply with this type of treatment, being more indicated necrosis of the proximal pole associated with nonunion as an attempt to improve bone blood supply.

Regarding DASH score, mean value was $5 \pm 5$ points which is considered an excellent end result, since the lower the score, the lower the degree of dysfunction. Kim et al. presented in their study DASH score $9 \pm 6$ using only volar percutaneous screw for treatment of scaphoid nonunion. ${ }^{10}$

The dynamometer tests showed a mean of $35 \mathrm{kgf}$, corresponding to $98 \%$ of unaffected hand strength, $37 \mathrm{kgf}$ (Figure 4), which remained within the normal range according to the literature. ${ }^{6}$

The average decrease in bending the affected side compared to the normal side was $7^{\circ}$ (affected side $68^{\circ}$ and unaffected side $75^{\circ}$ ) and the average decrease of the extension was 9 (affected side 63 and side affected not $72^{\circ}$ ) which was considered a good result (Figure 4). This was also confirmed by the low DASH score of patients.

The only patient who presented considerable loss of wrist 
Side comparison for strength, arc of movement and extension.

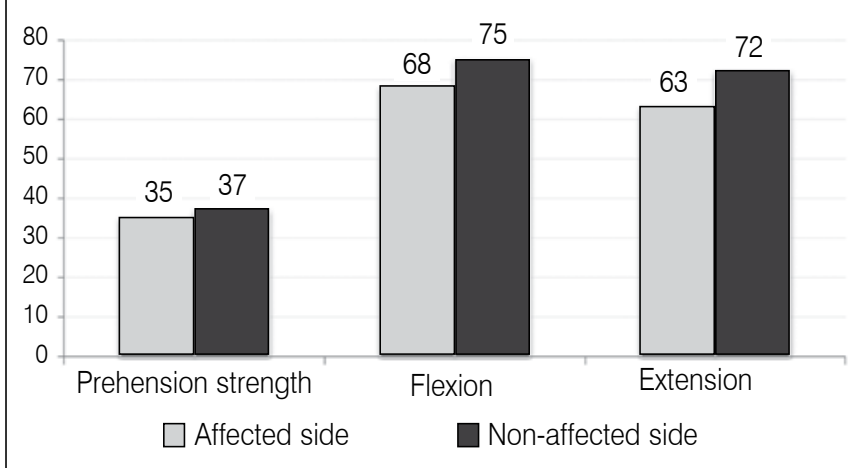

Figure 4. Side comparison for strength, arc of movement and extension. range of motion was on the seventh postoperative month and had not followed the guidelines of medical rehabilitation. He showed loss of flexion-extension accented handle $\left(31^{\circ}\right.$ extension and $28^{\circ}$ flexion) compared to the normal side, thus demonstrating the need for proper rehabilitation after surgery.

\section{CONCLUSION}

The small incision, lower visual exposure, and scar location on the back of the elbow are important aesthetic factors. Bone healing with preservation of limb functionality was obtained in all cases. The use of olecranon bone graft and cannulated screw fixation was a successful technique for Lichtmann type I scaphoid nonunion. We obtained a statistically significant difference between affected and non-affected sides regarding strength, arc of flexion and extension.

AUTHORS' CONTRIBUTION: ATNF (0000-0002-3680-2705) ${ }^{\star}$, EFT (0000-0002-5058-9920) ${ }^{\star}$, AP (0000-0002-2768-1657) ${ }^{\star}$ and NM (0000-0002-1239-7602)* were the main contributors in writing the manuscript. AT performed the surgeries, followed up the patients and collected clinical data. ET reassessed the patients and collected statistical data. AT and ET performed the bibliographic search. AP, NM and MR (0000-0001-9549-8830)* reviewed the manuscript and contributed to the study's intellectual concept. *ORCID (Open Research and Contributor ID)

\section{REFERENCES}

1. Geissler W, Slade JF. Fracture of the carpal bones. In: Wolfe SW, Hotchkiss RN, Pederson WC, Kozin SH, editors. Green's operative hand surgery. 6 th ed. Philadelphia: Churchill Livingstone/Elsevier; 2011. p. 639-707.

2. Rhemrev SJ, Ootes D, Beeres FJ, Meylaerts SA, Schipper IB. Current methods of diagnosis and treatment of scaphoid fractures. Int J Emerg Med. 2011;4:4.

3. Heo YM, Kim SB, Yi JW, Lee JB, Park CY, Yoon JY, et al. Evaluation of associated carpal bone fractures in distal radial fractures. Clin Orthop Surg.2013;5(2):98-104.

4. Gras M, Wahegaonkar AL, Mathoulin C. Treatment of Avascular Necrosis of the Proximal Pole of the Scaphoid by Arthroscopic Resection and Prosthetic Semireplacement Arthroplasty Using the Pyrocarbon Adaptive Proximal Scaphoid Implant (APSI): Long-Term Functional Outcomes. J Wrist Surg. 2012;1(2):159-64.

5. Leite NM. Fratura e luxações dos ossos do carpo. In: Pardini Junior AG, Freitas A. Traumatismos da mão. 2a.ed. Rio de Janeiro: Medbook; 2008. p. 487-544.

6. Freitas PP, Araújo PMP. Reabilitação funcional da mão. In: Pardini Júnior AG Freitas A. Cirurgia da mão: lesões não traumáticas. 2a.ed. Rio de Janeiro: Medbook; 2008. p.633-76.

7. McQueen MM, Gelbke MK, Wakefield A, Will EM, Gaebler C. Percutaneous screw fixation versus conservative treatment for fractures of the waist of the scaphoid: a prospective randomised study. J Bone Joint Surg Br. 2008;90(1):66-71.

8. Trumble TE, Salas $P$, Barthel T, Robert KQ 3rd. Management of scaphoid nonunions. J Am Acad Orthop Surg. 2003;11(6):380-91.

9. Zaidemberg C, Siebert JW, Angrigiani C. A new vascularized bone graft for scaphoid nonunion. J Hand Surg Am. 1991;16(3):474-8.

10. Kim JK, Kim JO, Lee SY. Volar percutaneous screw fixation for scaphoid waistdelayed union. Clin Orthop Relat Res. 2010;468(4):1066-71.

11. Yıldırım A, Unlüer EE, Vandenberk N, Karagöz A. The role of bedside ultrasonography for occult scaphoid fractures in the emergency department. Ulus Travma Acil Cerrahi Derg. 2013;19(3):241-5.

12. Valen B. Treatment of scaphoid fractures in a local hospital. Tidsskr Nor Laegeforen. 2013;133(10):1079-82.
13. Kirkham SG, Millar MJ. Cancellous bone graft and Kirschner wire fixation as a treatment for cavitary-type scaphoid nonunions exhibiting DISI. Hand (N Y). 2012;7(1):86-93.

14. León Santana P, Díaz Ramos H, Paredes González LF, Monreal González CR. Injerto óseo pediculado de pronador cuadrado en el tratamiento de la seudoartrosis de escafoides. Rev Cubana de Ortop Traumatol. 2008;22(2):1-7.

15. Malizos KN, Dailiana ZH, Varitimidis SE, Papatheodorou L. Scaphoid reconstruction with vascularized bone grafts from the distal radius. J Hand Microsurg. 2009; 1(1):50-3.

16. Giannoudis PV, Kanakaris NK, Dimitriou R, Gill I, Kolimarala V, Montgomery RJ. The synergistic effect of autograft and BMP-7 in the treatment of atrophic nonunions. Clin Orthop Relat Res. 2009;467(12):3239-48.

17. Ya'ish F, Bailey CA, Kelly CP, Craigen MA. Bioabsorbable fixation of scaphoid fractures and non-unions; analysis of early clinical outcomes. Hand Surg.2013;18(3):343-9.

18. Davidson AJ, Horwitz MT. an evaluation of excision in the treatment of ununited fracture of the carpal scaphoid (navicular) bone. Ann Surg. 1938;108(2):291-5.

19. Daruwalla ZJ, Davies K, Shafighian A, Gillham NR. An Alternative Treatment option for scaphoid nonunion advanced collapse (snac) and radioscaphoid osteoarthritis: early results of a prospective study on the pyrocarbon adaptive proximal scaphoid implant (APSI). Ann Acad Med Singapore. 2013;42(6):278-84.

20. Jafari D, Shariatzadeh $H$, Najd Mazhar F, Ghahremani $M H$. Ulnar variance in scaphoid nonunion. Arch Iran Med. 2013;16(5):301-2.

21. Abbassi N, Abdeljawad N, Erraji M, Abdelillah R, Daoudi A, Yacoubi H. Percutaneous tightening of the carpal scaphoid with Herbert' screw--about 10 cases. Pan Afr Med J. 2013;14:112.

22. Malizos KN, Dailiana ZH, Kirou M, Vragalas V, Xenakis TA, Soucacos PN. Longstanding nonunions of scaphoid fractures with bone loss: successful reconstruction with vascularized bone grafts. J Hand Surg Br. 2001;26(4):330-4.

23. Liang K, Ke Z, Chen L, Nie M, Cheng Y, Deng Z. Scaphoid nonunion reconstructed with vascularized bone-grafting pedicled on 1,2 intercompartmental supraretinacular artery and external fixation. Eur Rev Med Pharmacol Sci. 2013;17(11):1447-54 